\title{
A comparative study of renal function in male and female spiny mice - sex specific responses to a high salt challenge
}

\author{
Hayley Dickinson ${ }^{1 *}$, Karen M Moritz ${ }^{2}$ and Michelle M Kett $^{3}$
}

\begin{abstract}
Background: There is a significant body of evidence to suggest that hormone levels, receptor density and structural differences between males and females can significantly alter renal hemodynamics. We compared the renal hemodynamic and excretory profile of female and male spiny mice under baseline conditions and in response to a high- $\mathrm{NaCl}$ diet.
\end{abstract}

Methods: Adult male and female spiny mice were fed either a normal or high salt diet for 7 days. Renal excretory profile was obtained from $24 \mathrm{~h}$ urine samples, and renal hemodynamic measurements using anaesthetised renal clearance techniques. Kidneys were excised, weighed and frozen for qPCR analysis.

Results: Under basal conditions, conscious and anaesthetised renal functions were similar between male and female spiny mice when adjusted for body weights. Male and female spiny mice on the high- $\mathrm{NaCl}$ diet had significantly greater GFR than sex matched controls $\left(P_{\text {DIET }}<0.001\right)$. However the magnitude of the effect of salt was sex dependent $\left(P_{\text {SEX }}<0.001 ; P_{\text {INT }}<0.01\right)$. Male spiny mice showed a greater increase in GFR (84\% higher than normal salt males) compared to females (33\% higher than normal salt females), despite similar increases in renal plasma flow. In response to 7 days of high salt diet, female spiny mice showed a greater increase in 24-hour water consumption ( $45 \%$ more) and urinary output $\left(50 \%\right.$ more) compared to males ( $\left.P_{\text {INT }}<0.01\right)$. These sex differences could not be explained by differences in renal expression of the V2R or AQP3 channel.

Conclusion: These studies have identified major differences between male and female spiny mice in their renal response to a high- $\mathrm{NaCl}$ load suggesting that renal hemodynamics may be differentially regulated for the sexes.

Keywords: Kidney, Acomys cahirinus, $\mathrm{NaCl}$

\section{Background}

Rodent species such as the rat and mouse have been, and will continue to be, crucial in our understanding of human health and disease. However in the fields of fetal programming and suboptimal pregnancy, they have a distinct drawback in their utility as models of human pregnancy. Typical rodents have relatively short gestation periods (18-21 days), giving birth to large litters of offspring in which development of major organs, including the kidney, is incomplete at birth and continues well into the neonatal period. The spiny mouse (Acomys cahirinus)

\footnotetext{
*Correspondence: Hayley.Dickinson@monash.edu

'The Ritchie Centre, Monash Institute of Medical Research, Monash University, Clayton, VIC, Australia

Full list of author information is available at the end of the article
}

is a nocturnal species native to regions of Egypt and Israel, where it inhabits sandy deserts and rocky terrains giving birth to 1-3 young [1]. In stark contrast to typical rodents, organogenesis of the spiny mouse kidney [2], liver [3], lung [4] and various brain regions [5-7] are completed during the 39-day period of fetal life, and thus spiny mice are born at a developmental stage comparable to the human newborn. Indeed the spiny mouse is the only known rodent species to complete nephrogenesis before birth [2]. Owing to this, and the comparable endocrinology of pregnancy [8], the spiny mouse is now being utilized as a preclinical model of sub-optimal human pregnancy. Using this species, we have developed robust and repeatable models of birth asphyxia [9-13], maternal viral infection [14] and excess maternal glucocorticoids

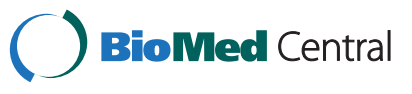


[15-17]. These studies of sub-optimal pregnancy in the spiny mouse have highlighted numerous sex-specific differences including placental gene expression and structural development $[15,16,18]$, postnatal growth and survival after birth asphyxia [11] and susceptibility to adult renal dysfunction [17] after excess maternal glucocorticoid exposure in utero.

There is a growing body of evidence to suggest that hormone levels, receptor density and structural differences between males and females can significantly alter renal hemodynamics $[19,20]$. These differences may be implicated in the sexually dimorphic incidence of diseases such as diabetic nephropathy, acute and chronic ischemic renal failure, aging, and susceptibility to adult renal disease following an adverse intrauterine environment [21]. It is generally considered that males drink less, and are able to concentrate their urine more than females contributing to the higher risk of urolithiasis [22-24], however the mechanisms are poorly described [20]. The current study aimed to determine whether fundamental differences in renal function exist between the sexes in adult spiny mice. Secondly, as differences are often only exposed following a challenge, we also examined the response of male and female spiny mice to a high salt diet. We hypothesized that spiny mice will exhibit sex specific responses to a high- $\mathrm{NaCl}$ load and that this will be reflected in differences in renal excretory and hemodynamic profiles.

\section{Methods}

\section{Animals}

All experiments were approved in advance by Monash University School of Biomedical Sciences Animal Ethics Committees and conducted in accordance with the Australia Code of Practice for the Care and Use of Animals for Scientific Purposes. Adult (13-15 week old) male $(n=26)$ and female $(n=25)$ spiny mice used in this study were obtained from our own laboratory colony as previously described [2].

\section{Conscious renal function}

Trained spiny mice ( $\mathrm{n}=16$ male, 15 female) were placed in metabolic cages to obtain baseline $24 \mathrm{~h}$ urine samples on a normal salt diet $(0.25 \% \mathrm{w} / \mathrm{w} \mathrm{NaCl}$; Specialty Feeds, WA, Australia). Spiny mice were then allocated to receive a high salt diet $(10 \% \mathrm{w} / \mathrm{w} \mathrm{NaCl}$; Specialty Feeds, WA, Australia) or remain on normal salt chow (5/sex/diet), and measurements repeated on days 3 and 7 . A high, 10\% w/w, $\mathrm{NaCl}$ diet was chosen as the spiny mouse is a desert species and high-salinity vegetation or invertebrates are often the only available source of nutrients and water [25]. Metabolic cage data collected on days 3 and 7 did not differ; therefore only data collected on day 7 are presented. Further, the data obtained on days 3 and 7 for normal salt male and female time controls did not differ from baseline values and are not presented.

\section{Urine collection and analysis}

Body mass, water and food consumption, and faeces and urine excretion were recorded for all spiny mice. Urine was collected and frozen for subsequent analysis of urinary electrolytes. All urine samples were analysed for sodium $(\mathrm{Na})$, chloride $(\mathrm{Cl})$, potassium $(\mathrm{K})$ and urea by spectrophotometry (Synchron CX5CE Delta; Beckman Coulter, Fullerton, CA, USA). Osmolality of urine and plasma samples was measured by freezing point depression (Advanced Osmometer 2020; Advanced Instruments, Needham Heights, MA). Protein concentration of urine samples was measured by BCA Protein Assay (Kit\#23225, Thermo Scientific, Australia).

\section{Anaesthetised renal function}

Spiny mice $(n=5 /$ sex/diet) were maintained on either a normal salt diet $(0.25 \% \mathrm{w} / \mathrm{w} \mathrm{NaCl}$; Specialty Feeds, WA, Australia) or placed on a high salt diet $(10 \% \mathrm{w} / \mathrm{w} \mathrm{NaCl})$ for 7 days prior to anaesthetised renal function measurements (data obtained from males in this cohort has been published in part [26]). Briefly, spiny mice were anaesthetised (Isoflurane mixed with $40 \% \mathrm{O}_{2}, 60 \% \mathrm{~N}_{2}$; 4.5\% induction, 2.5-2.8\% maintenance; Rhodia Australia $\mathrm{P} / \mathrm{L}$, Notting Hill, VIC, Australia) and placed on a heated pad to maintain body temperature at $37.5^{\circ} \mathrm{C}$. A catheter (tapered SV-35 tubing) was inserted into the right carotid artery for continuous measurement of blood pressure and heart rate (HR), and to obtain a terminal arterial blood sample. The left jugular vein was catheterized (PE-10 tubing) for infusion of a $1 \%$ bovine serum albumin (BSA) solution containing ${ }^{3} \mathrm{H}$-inulin $(5.58 \mu \mathrm{Ci} / \mathrm{mL})$ and ${ }^{14} \mathrm{C}$-paraaminohippurate (PAH; $1.7 \mu \mathrm{Ci} / \mathrm{mL}$ ) for estimation of glomerular filtration rate (GFR) and effective renal plasma flow (ERPF) respectively by renal clearance methods [26,27]. The bladder was catheterised to allow the collection of urine, and the mice were allowed to equilibrate for $1 \mathrm{~h}$. Following equilibration, urine was collected over two timed 15 min periods after which an arterial blood sample was taken. Animals were killed at the completion of the renal function measurements and kidney samples frozen and fixed for further analysis.

\section{Real-time PCR}

Real-time PCR primer design for Aquaporin 3 (AQP3; GenBank NM_004925.4, NM_016689.2) and vasopressin type 2 receptor (V2R; GenBank NM_019404.2, NM_019136.1, NM_001146151.1) was performed as previously described [15]. Briefly, for each gene of interest, where possible the cDNA sequences for Mus musculus, Rattus norvegicus, and Homo sapiens were aligned, and primers were designed based on identified regions of high 
homology. Optimizing PCR assays were conducted in order to test the specificity of the primer sets, which were found to amplify products of the expected sizes (data not shown). Primers for other aquaporin's could not be designed for the spiny mouse because of lack of sufficient sequence homology between other species.

RNA was extracted from whole adult kidneys using the commercially available RNeasy Midi kit (Qiagen, Australia) and samples (1 ug RNA) were reverse transcribed to form cDNA. Quantitative real-time PCR (qPCR) cycling conditions for all genes consisted of an initial denaturation step of $95^{\circ} \mathrm{C}$ for $10 \mathrm{~min}$, followed by 40 cycles consisting of $95^{\circ} \mathrm{C}$ for $15 \mathrm{sec}$ and $60^{\circ} \mathrm{C}$ for $1 \mathrm{~min}$. A dissociation curve was also performed at the end of each run. Samples were run in duplicate for each gene of interest. A comparative CT (cycle of threshold fluorescence) method was used for analysis with $18 \mathrm{~S}$ used as an endogenous reference [15]. To calculate the relative expression levels in each sample, the $\mathrm{CT}$ value for $18 \mathrm{~S}$ was subtracted from the $\mathrm{CT}$ value of the gene of interest to give a $\Delta C T$ value. The mean $\Delta C T$ value of the saline group was then subtracted from each individual sample to give a $\Delta \Delta \mathrm{CT}$. This number was then inserted into the formula $2^{-\Delta \Delta C T}$ to give the expression level relative to the mean of the male normal salt diet group. The assay was run twice for each gene of interest.

\section{Data analysis and statistics}

Data are presented as means \pm SEM. Two-way ANOVA (repeated where appropriate), with diet $\left(\mathrm{P}_{\mathrm{DIET}}\right)$ and sex $\left(\mathrm{P}_{\mathrm{SEX}}\right)$ as the fixed factors, was used to determine whether the impact of the salt diet on renal variables were different between males and females. $\mathrm{P}_{\text {INT }}$ refers to an interaction effect between diet and sex. Bonferoni posthoc analysis was used where stated. $\mathrm{P}$ values of $\leq 0.05$ were considered statistically significant.

\section{Results}

\section{Conscious renal function}

Male spiny mice were approximately $14 \%$ heavier than age-matched females at the time of baseline measurements taken on a normal salt diet. When corrected for body weight, water and food intake and urine excretion were similar between the sexes (Table 1). The urinary excretion of sodium, urea, osmolites and urine osmolality were also similar between male and female spiny mice when corrected for bodyweight (Table 1).

The 7 days of high salt diet did not effect bodyweight or food intake in male or female spiny mice (Figure 1). Male and female spiny mice showed a significant increase in water consumption and urine output in response to the high salt diet $\left(\mathrm{P}_{\mathrm{DIET}}<0.001\right.$; Figure 1$)$. There was a significant effect of sex on both water consumption $\left(\mathrm{P}_{\mathrm{SEX}}=0.005\right)$ and urine excretion $\left(\mathrm{P}_{\mathrm{SEX}}=0.007\right)$. Post-hoc
Table 124 hour renal function in male and female spiny mice

\begin{tabular}{lll}
\hline & Male & Female \\
\hline Body Weight (g) & $36.6 \pm 0.7$ & $32.0 \pm 0.6^{*}$ \\
Water Intake (ul/gBW) & $101.8 \pm 6.3$ & $112.2 \pm 14.4$ \\
Urine Volume (ul/gBW) & $37.2 \pm 3.1$ & $35.3 \pm 6.5$ \\
Food Intake (mg/gBW) & $86.6 \pm 4.1$ & $79.9 \pm 7.1$ \\
$\mathbf{N a}^{+}$Excretion (umol/g BW) & $2.52 \pm 0.26$ & $2.46 \pm 0.40$ \\
Urea Excretion (umol/g BW) & $53.2 \pm 3.2$ & $45.4 \pm 7.1$ \\
Osmolality (mOsmol/kg H2O) & $2546 \pm 419$ & $2247 \pm 286$ \\
Osmolar Excretion (uosmol/g BW) & $90.4 \pm 13.2$ & $70.6 \pm 11.6$ \\
$\mathbf{n}$ & 16 & 15 \\
\hline
\end{tabular}

Values are mean \pm SEM. ${ }^{*} \mathrm{P}<0.001$.

analysis showed that whilst baseline water consumption and urine output between the sexes were not significantly different, on a high salt diet female spiny mice consumed $45 \%$ more water and excreted 50\% more urine than males $(\mathrm{P}<0.01 ; \mathrm{P}<0.05)$. Male and female spiny mice exhibited a similar, marked increase in urinary $\mathrm{Na}$, and protein, on the high salt diet, however there was no difference in the response of the sexes to the high salt diet $\left(\mathrm{P}_{\mathrm{DIET}}<0.001\right.$; $\mathrm{P}_{\mathrm{SEX}}=\mathrm{NS}$; Figure 1). Total osmolar excretion increased, and urine osmolality fell in response to the high salt diet, an effect that was similar between the sexes (Data not shown). Urinary excretion of $\mathrm{K}$ was similar between the sexes and did not change with high salt diet (Data not shown).

\section{Anaesthetised renal function}

Anaesthetised renal function values for male and female spiny mice following 7 days of high salt or normal salt diet are described in Table 2. Anaesthetised MAP, ERPF, and RVR values were similar between the sexes (Table 2). ERPF was approximately 55\% greater in males and females on the high salt diet compared to normal salt controls $\left(\mathrm{P}_{\text {DIET }}<0.001\right)$. MAP was mildly but significantly $\left(\mathrm{P}_{\mathrm{DIET}}=0.04\right)$ greater in high salt compared to normal salt groups resulting in a markedly lower RVR in high salt compared to normal salt groups $\left(\mathrm{P}_{\mathrm{DIET}}=0.002\right.$; Table 2$)$. There was however no difference in the response of the sexes to the high salt diet for ERPF, MAP or RVR $\left(\mathrm{P}_{\text {INT }}=\right.$ NS; Table 2$)$.

High salt diet and sex had significant effects on GFR. Male and female spiny mice on the high salt diet had significantly greater GFR than sex matched controls $\left(\mathrm{P}_{\text {DIET }}<0.001\right)$. However the magnitude of the effect of salt was sex dependent $\left(\mathrm{P}_{\mathrm{SEX}}=0.005 ; \mathrm{P}_{\mathrm{INT}}=0.025\right.$; Table 2). The effect of high salt diet was greatest in males, with the GFR of high salt males $84 \%$ higher than normal salt controls whereas females on high salt had GFR values that were only $33 \%$ higher than normal salt 


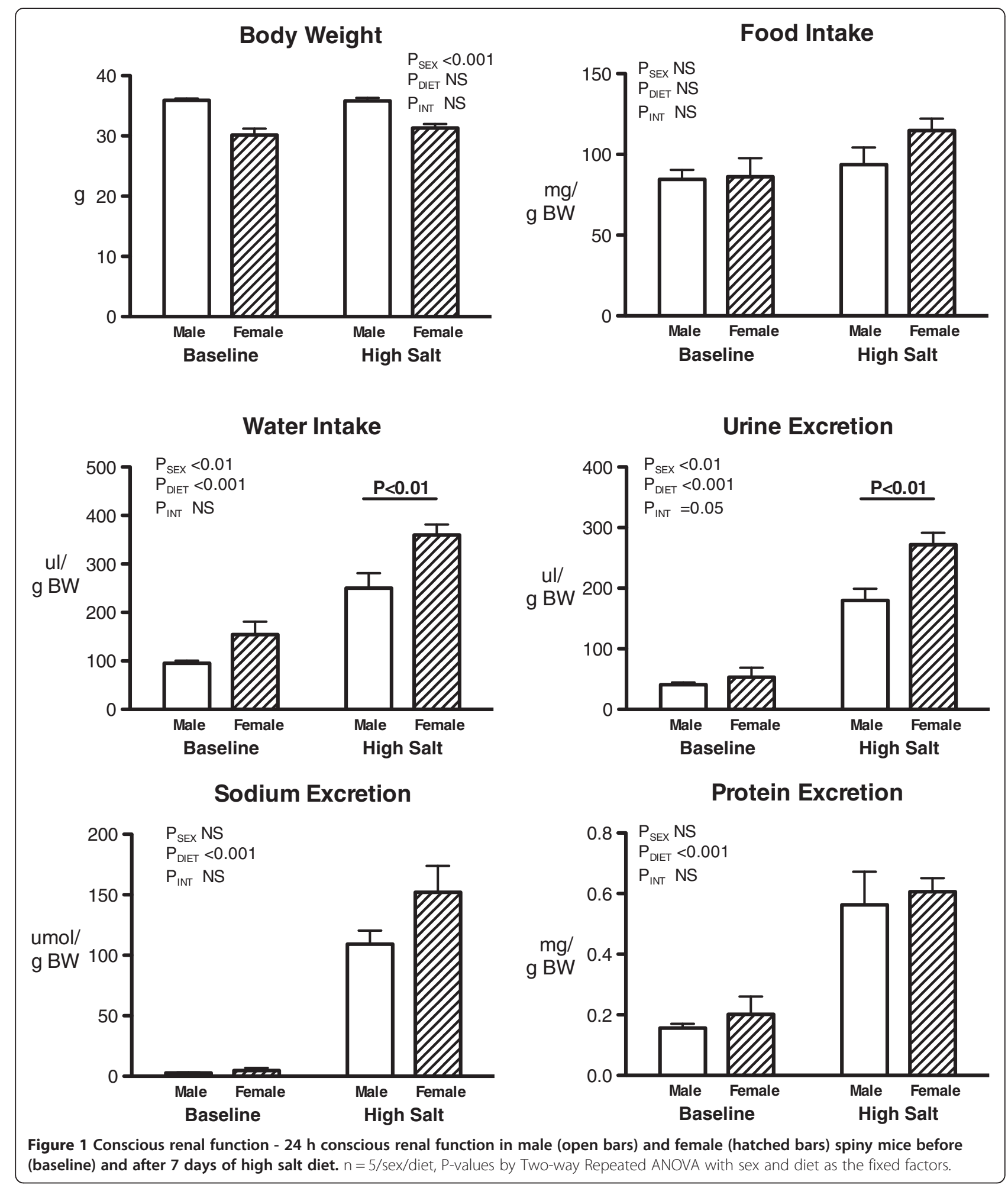

controls $\left(\mathrm{P}_{\mathrm{INT}}=0.025\right.$; Table 2$)$. As a result of the sexually dimorphic response of GFR but not ERPF to high salt diet, filtration fraction of male spiny mice on the high salt diet was higher than normal salt controls, whereas in females, filtration fraction on the high salt diet was lower than controls $\left(\mathrm{P}_{\mathrm{INT}}=0.048\right.$; male, 32-37\%; female, 32-27\%; Table 2).

Body mass was greater in male than female spiny mice $\left(\mathrm{P}_{\mathrm{SEX}}<0.001\right.$; Table 2$)$ however there was no effect of salt diet on body mass or the change in body mass over 
Table 2 Anaesthetised renal function and PCR analysis of male and female spiny mice on normal or high salt diets

\begin{tabular}{|c|c|c|c|c|c|c|c|}
\hline & \multicolumn{2}{|l|}{ Male } & \multicolumn{2}{|l|}{ Female } & \multicolumn{3}{|c|}{ Statistics } \\
\hline & Normal salt & High salt & Normal salt & High salt & $\overline{P_{\text {SEX }}}$ & $P_{\text {DIET }}$ & $\mathrm{P}_{\mathrm{INT}}$ \\
\hline \multicolumn{8}{|l|}{ Mass } \\
\hline Pre-diet Body Mass g & $35.8 \pm 0.4$ & $35.7 \pm 0.9$ & $33.5 \pm 1.0$ & $31.8 \pm 0.7$ & $=0.001$ & 0.29 & 0.35 \\
\hline Post-diet Body Mass g & $36.8 \pm 0.6$ & $37.1 \pm 0.6$ & $33.9 \pm 0.8$ & $32.0 \pm 0.9$ & $<0.001$ & 0.29 & 0.16 \\
\hline Change in Body Mass g & $1.0 \pm 0.3$ & $1.4 \pm 0.6$ & $0.4 \pm 0.4$ & $0.2 \pm 0.3$ & 0.052 & 0.84 & 0.46 \\
\hline Kidney Mass mg & $268 \pm 11$ & $295 \pm 10$ & $263 \pm 9$ & $285 \pm 8$ & 0.42 & $=0.01$ & 0.80 \\
\hline KM: BM Ratio mg:g & $7.27 \pm 0.23$ & $7.97 \pm 0.18$ & $7.75 \pm 0.16$ & $8.95 \pm 0.33$ & $=0.005$ & $<0.001$ & 0.29 \\
\hline \multicolumn{8}{|c|}{ Renal \& Cardiovascular Measures } \\
\hline MAP $\mathrm{mmHg}$ & $62.0 \pm 1.5$ & $67.4 \pm 1.7$ & $60.3 \pm 2.0$ & $62.4 \pm 1.6$ & 0.07 & $=0.04$ & 0.36 \\
\hline $\mathrm{GFR} \mu \mathrm{L} / \mathrm{min} / \mathrm{gBM}$ & $3.66 \pm 0.12$ & $6.63 \pm 0.34$ & $3.43 \pm 0.28$ & $4.83 \pm 0.51$ & $=0.005$ & $<0.001$ & $=0.025$ \\
\hline $\mathrm{ERPF} \mu \mathrm{L} / \mathrm{min} / \mathrm{gBM}$ & $11.60 \pm 0.54$ & $18.36 \pm 1.38$ & $11.51 \pm 1.80$ & $17.61 \pm 1.38$ & 0.76 & $<0.001$ & 0.81 \\
\hline $\mathrm{RVR} \mathrm{mmHg} / \mu \mathrm{L} / \mathrm{min} / \mathrm{gBM}$ & $3.03 \pm 0.10$ & $2.12 \pm 0.17$ & $3.35 \pm 0.48$ & $2.09 \pm 0.15$ & 0.62 & $=0.002$ & 0.55 \\
\hline Filtration Fraction $\%$ & $32 \pm 2$ & $37 \pm 3$ & $32 \pm 3$ & $27 \pm 1$ & 0.07 & 0.95 & $=0.048$ \\
\hline \multicolumn{8}{|l|}{ Renal PCR } \\
\hline AQP3 & $1.00 \pm 0.13$ & $0.72 \pm 0.14$ & $0.75 \pm 0.14$ & $0.73 \pm 0.09$ & 0.46 & 0.22 & 0.28 \\
\hline V2R & $1.00 \pm 0.15$ & $0.79 \pm 0.20$ & $0.67 \pm 0.12$ & $0.91 \pm 0.14$ & 0.32 & 0.64 & 0.28 \\
\hline
\end{tabular}

Values are means \pm SEM. $\mathrm{n}=6$ per sex on normal salt diet, $\mathrm{n}=5$ per sex on high salt diet. $N S$, non significant, g; gram, $B M$, body mass, $K M$, kidney mass, $M A P$, mean arterial pressure, GFR, glomerular filtration rate, ERPF, effective renal plasma flow, $R V R$, renal vascular resistance. Data were analysed by Two way ANOVA.

the 7 days of dietary treatment in either sex. There was no sex difference in total kidney mass, thus kidney to body mass ratio was higher in females compared to males $\left(\mathrm{P}_{\mathrm{SEX}}<0.001\right.$; Table 2$)$. High salt diet had a significant impact on kidney mass leading to greater kidney mass $\left(\mathrm{P}_{\text {DIET }}=0.01\right.$; Table 2$)$ and kidney to body mass ratios $\left(\mathrm{P}_{\text {DIET }}<0.001\right.$; Table 2$)$ compared to normal salt controls in males and females. Heart rate (male normal salt (NS) $472 \pm 8$, high salt (HS) $464 \pm 16$; female NS $492 \pm 10$, HS $476 \pm 14 \mathrm{bpm})$ and plasma osmolality (male NS $332 \pm 6$, HS $361 \pm 17$; female NS $343 \pm 22$, HS $348 \pm 11 \mathrm{mosmol} / \mathrm{kg} \mathrm{H}_{2} \mathrm{O}$ ) did not differ between the sexes or salt groups.

\section{Real-time PCR}

The renal expression of AQP3 and V2R did not differ between male and female spiny mice and was not effected by the level of dietary salt (Table 2).

\section{Discussion and conclusions}

The spiny mouse is a unique species amongst rodents due to the fact that nephrogenesis, in addition to development of other organs, is completed prior to birth [2]. As such it has a distinct advantage over other rodents as a preclinical model of human pregnancy. We have detected distinct sexual dimorphic responses of the fetal/ placental unit and the kidney specifically, to sub-optimal pregnancy $[16,17]$. However we do not have a good understanding of basic sex differences in renal physiology in adult spiny mice and how they compare with other rodent species and, importantly, humans. Our study aimed to determine whether there were sex differences in renal function of adult spiny mice under baseline conditions and in response to the challenge of a 7-day high salt diet. We found there was little difference in basal renal function between male and female spiny mice when differences in body weight were accounted for. However we detected a dramatic, sexually dimorphic response when mice were challenged with a high salt diet. These findings suggest that males and females respond to a high-salt load by different mechanisms, and may contribute to the greater susceptibility to renal disease in males.

\section{Basal sex differences in renal function}

Under basal conditions we found that both conscious and anaesthetised renal function were similar between male and female spiny mice. When corrected for bodyweight, 24-hour food and water intake, urine production, and the excretion of sodium and osmolytes were similar in male and female spiny mice. In anaesthetised experiments we again found that renal function was similar with renal plasma flow, renal vascular resistance and filtration fraction not different between the sexes. Although 2-way ANOVA detected a significant sex effect for GFR, this result was likely driven by the large effect of salt in males. Indeed on normal salt, GFR in males was only $7 \%$ greater than females. Thus under controlled, low dietary salt conditions, male and female spiny mice show similar renal function relative to bodyweight.

Evidence from human and animal studies suggests that there are significant differences in renal physiology 
between the sexes due to differences in vascular responsiveness and the level of expression and action of renal transporters [19]. For example, studies in rats have shown that whole kidney GFR and single nephron GFR are higher in males than females due to a higher renal plasma flow and lower renal vascular resistance, that result in sustained hyperfiltration in males [28-30]. However, consistent with our anaesthetised renal function findings, most studies have demonstrated that when indices of renal function have been factored for the higher bodyweight or kidney weights of males, these sex differences are greatly diminished [29]. Studies in rodents and human also suggest that females drink more and excrete a greater volume, of less concentrated, urine [20,22-24]. However in a review of the human literature, Perucca et al. [20] noted that whilst $24 \mathrm{~h}$ urine volumes in 4 of 9 studies were a modest $10-14 \%$ lower in males, in the remaining 5 studies urine volumes were similar between the sexes as in our study of the spiny mouse.

\section{Sex-specific renal adaptations to a high salt load}

When challenged with a high salt load, significant differences in renal function were observed between male and female spiny mice. Female spiny mice fed a high salt diet for 7 days demonstrated a significantly greater increase in water consumption and urine production when compared to male spiny mice. In contrast, whilst both female and male spiny mice on a high salt diet had significantly greater GFR, renal plasma flow and MAP compared to control spiny mice, the increase in GFR of the male spiny mice on the high salt diet was significantly greater than female spiny mice, despite similar increases in renal plasma flow. The major finding therefore of these studies is that there are sex specific differences in the renal response of spiny mice to a high-salt load.

Consistent with our findings, studies in humans have found that males excrete high osmolar loads by increasing urinary concentration rather than increases in urine volume [20]; a feature that has been linked to the higher rates of urolithiasis in males $[19,20]$. The mechanisms underlying the higher urine excretion and drinking rates of female compared to male spiny mice on the high salt diet are unclear but may be due to sex differences in levels of, and sensitivity to, vasopressin. Some studies have reported higher plasma and urinary vasopressin levels in men [20]. These higher levels of vasopressin in males may be due to greater secretion as several studies have found that vasopressin secretion in males is more sensitive to osmotic stimuli (e.g., hypertonic saline infusion); see [20,31-33]. Further, levels of V2 receptors have also been found to be higher in male rats [33]. Sex steroids are likely to contribute to these differences with Longhurst and colleagues showing that estradiol treatment of ovariectomized rats caused significant increases in water consumption and urine excretion when compared to ovariectomized and sham-operated rats [34]. The authors concluded that estrogen attenuates the antidiuretic effect of vasopressin, a finding that was further supported by Wang et al. [24], who found that the antidiuretic activity of vasopressin was effected by the estrous cycle.

We investigated whether the renal expression of vasopressin receptors and aquaporins would differ between the sexes providing a mechanism for the different sensitivity of the sexes to high salt. Unfortunately, due to low species homology between the aquaporins (in regions of the genes appropriate for primer design) we were unable to examine AQP1, which is directly involved in urinary concentration in the proximal tubule and descending thin limb, or AQP2 which is the predominant vasopressin-regulated water channel expressed in the connecting tubule and collecting duct [35]. We were able to examine AQP3 which is primarily expressed in the collecting duct where it is reported to have a role in osmotically driven water absorption across the collecting duct epithelium with AQP4 [36], however the expression of AQ3 did not differ between the sexes. Despite findings in rats that males have higher expression of V2R compared to females [33], we found that the expression of V2R did not differ between the sexes suggesting that it is not a difference in transcription of the vasopressin receptor that mediates the sex differences observed here. Indeed, further work to examine other aquaporins as well as plasma vasopressin levels between the sexes is warranted.

Our study has identified a sexual dimorphic renal hemodynamic response to high salt diet. On the high salt diet both sexes demonstrated a fall in renal vascular resistance and concomitant increase in renal plasma flow. This drop in resistance also facilitated an increase in GFR, however there was a significant difference between the sexes in the magnitude of the response. The GFR of high salt males was $84 \%$ higher than normal salt controls, whereas females on high salt had GFR values that were only 33\% higher than normal salt controls. An enhanced renal function response to high salt diet has also been reported in men. Interestingly, whilst young men showed increases in GFR and renal plasma flow in response to chronic saltloading [37], women (luteal or follicular phase) did not show these increases in renal function [38]. Sex steroids, sexual dimorphism in the renin angiotensin and endothelin systems have been implicated in the differential response to high salt diet $[39,40]$.

The higher GFR in males compared to females, with no difference between the sexes for RVR, suggests that there was a significant difference in the ratio of pre to post-glomerular resistance changes between the sexes. Significantly the data suggests that the males showed significantly greater preglomerular vascular dilation than 
female spiny mice. As this would indicate significantly greater glomerular capillary pressure in males versus females, it would suggest that prolonged, chronic exposure to high salt would lead to greater hyperfiltration induced injury in males compared to females. Consistent with this hypothesis, studies in humans and animal models have shown that males show an accelerated age-related decline in renal function and are more sensitive to acute and chronic renal injury $[19,29,41]$.

In summary, our studies have highlighted that when adjusted for bodyweight, renal excretory and hemodynamic function of the spiny mouse are similar between the sexes under control conditions. However we identified a sexually dimorphic response to the physiological challenge of a high salt load. Male spiny mice were able to excrete the salt load in a reduced urine volume compared to females. Further, male spiny mice showed an exaggerated rise in GFR on the high salt load consistent with greater preglomerular dilatation. These responses may contribute to the greater susceptibility of males to renal disease.

\section{Abbreviations}

GFR: Glomerular filtration rate; ERPF: Effective renal plasma flow;

ERBF: Effective renal blood flow; RVR: Renal vascular resistance; $\mathrm{NaCl}$ : Sodium chloride; AQP: Aquaporin; V2R: Vasopressin type 2 receptor; MAP: Mean arterial pressure; HS: High salt; NS: Normal salt; bpm: Beats per minute; ANOVA: Analysis of variance; CT: Cycle threshold; BSA: Bovine serum albumin; PAH: Paraaminohippurate; PCR: Polymerase chain reaction; RNA: Ribonucleic acid.

\section{Competing interests}

The authors do not have any competing interests to declare.

\section{Authors' contributions}

HD contributed to study conception and design, carried out animal work and performed all urine analysis and GPCR. KMM contributed to study conception and design. MMK contributed to study conception and design, performed animal work with HD and prepared the final results and performed statistical analysis. All authors read and approved the final manuscript.

\section{Acknowledgements}

The authors thank A/Prof. David Walker, Monash University, for providing the spiny mice used in this study. Hayley Dickinson is an Australian Research Council (ARC) Australian Post-doctoral fellow; Karen Moritz is supported by a NHMRC Fellowship; Michelle M Kett is supported by a National Heart Foundation Fellowship (G 04 M 1551) and NHMRC project grant (491042). The Victorian Government's Operational Infrastructure Support Program supports this work.

\section{Author details}

${ }^{1}$ The Ritchie Centre, Monash Institute of Medical Research, Monash University, Clayton, VIC, Australia. ${ }^{2}$ School of Biomedical Sciences, University of Queensland, Brisbane, Australia. ${ }^{3}$ Department of Physiology Monash University, Clayton, Australia.

Received: 11 July 2013 Accepted: 26 November 2013

Published: 10 December 2013

\section{References}

1. Walker E: Mammals of the world. 2nd edition. The John Hopkins Press; 1968.

2. Dickinson H, Walker DW, Cullen-McEwen L, Wintour EM, Moritz K: The spiny mouse (Acomys cahirinus) completes nephrogenesis before birth. Am J Physiol Renal Physiol 2005, 289:F273-F279.
3. Lamers WH, Mooren PG, De Graaf A, Charles R: Perinatal development of the liver in rat and spiny mouse. Its relation to altricial and precocial timing of birth. Eur J Biochem 1985, 146:475-480.

4. Oosterhuis WP, Mooren PG, Charles R, Lamers WH: Perinatal development of the lung in rat and spiny mouse: its relation to altricial and precocial timing of birth. Biol Neonate 1984, 45:236-243.

5. Brunjes PC: Olfactory bulb maturation in Acomys cahirinus: is neural growth similar in precocial and altricial murids? Brain Res 1983, 284:335-341.

6. Brunjes PC: A stereological study of neocortical maturation in the precocial mouse, Acomys cahirinus. Brain Res 1985, 351:279-287.

7. Brunjes PC: A comparative study of prenatal development in the olfactory bulb, neocortex and hippocampal region of the precocial mouse Acomys cahirinus and rat. Brain Res Dev Brain Res 1989, 49:7-25.

8. Quinn TA, Ratnayake U, Dickinson H, Nguyen TH, Mclntosh M, CastilloMelendez M, Conley AJ, Walker DW: Ontogeny of the adrenal gland in the spiny mouse, with particular reference to production of the steroids cortisol and dehydroepiandrosterone. Endocrinology 2013, 154:1190-1201.

9. Ireland Z, Castillo-Melendez M, Dickinson H, Snow R, Walker DW: A maternal diet supplemented with creatine from mid-pregnancy protects the newborn spiny mouse brain from birth hypoxia. Neuroscience 2011, 194:372-379.

10. Ireland Z, Dickinson H, Fleiss B, Hutton LC, Walker DW: Behavioural effects of near-term acute fetal hypoxia in a small precocial animal, the spiny mouse (Acomys cahirinus). Neonatology 2010, 97:45-51.

11. Ireland Z, Dickinson H, Snow R, Walker DW: Maternal creatine: does it reach the fetus and improve survival after an acute hypoxic episode in the spiny mouse (Acomys cahirinus)? Am J Obstet Gynecol 2008, 198:431. e431-436.

12. Dickinson H, Ireland ZJ, LaRosa DL, O'Connell B, Ellery SJ, Snow R, Walker DW: Maternal dietary creatine supplementation does not alter the capacity for creatine synthesis in the newborn spiny mouse. Reproductive Sci 2013. In Press.

13. Ellery SJ, Ireland Z, Kett MM, Snow R, Walker DW, Dickinson H: Creatine pretreatment prevents birth asphyxia-induced injury of the newborn spiny mouse kidney. Pediatr Res 2013, 73:201-208.

14. Ratnayake U, Quinn TA, Castillo-Melendez M, Dickinson H, Walker DW: Behaviour and hippocampus-specific changes in spiny mouse neonates after treatment of the mother with the viral-mimetic Poly $\mathrm{I} C \mathrm{C}$ at mid-pregnancy. Brain Behav Immun 2012, 26:1288-1299.

15. O'Connell BA, Moritz KM, Roberts CT, Walker DW, Dickinson H: The placental response to excess maternal glucocorticoid exposure differs between the male and female conceptus in spiny mice. Biol Reprod 2011, 85:1040-1047.

16. O'Connell BA, Moritz KM, Walker DW, Dickinson H: The synthetic glucocorticoid dexamethasone inhibits branching morphogenesis in the spiny mouse placenta. Biol Reprod 2013, 88:26.

17. Dickinson H, Walker DW, Wintour EM, Moritz K: Maternal dexamethasone treatment at midgestation reduces nephron number and alters renal gene expression in the fetal spiny mouse. Am J Physiol - Regul Integr Comp Physiol 2007, 292:R453-R461.

18. O'Connell BA, Moritz KM, Walker DW, Dickinson H: Sexually dimorphic placental development throughout gestation in the spiny mouse (Acomys cahirinus). Placenta 2012, 34:119-126.

19. Sabolic I, Asif AR, Budach WE, Wanke C, Bahn A, Burckhardt G: Gender differences in kidney function. Pflugers Arch 2007, 455:397-429.

20. Perucca J, Bouby N, Valeix P, Bankir L: Sex difference in urine concentration across differing ages, sodium intake, and level of kidney disease. Am J Physiol Regul Integr Comp Physiol 2007, 292:R700-R705.

21. Yanes LL, Sartori-Valinotti JC, Reckelhoff JF: Sex steroids and renal disease: lessons from animal studies. Hypertension 2008, 51:976-981.

22. Kuo SM, MacLean ME, McCormick K, Wilson JX: Gender and sodiumascorbate transporter isoforms determine ascorbate concentrations in mice. J Nutr 2004, 134:2216-2221.

23. Schmidt F, Yoshimura Y, Ni RX, Kneesel S, Constantinou CE: Influence of gender on the diurnal variation of urine production and micturition characteristics of the rat. Neurourol Urodyn 2001, 20:287-295.

24. Wang YX, Crofton JT, Liu H, Brooks DP, Share L: Effects of gonadectomy on sexually dimorphic antidiuretic action of vasopressin in conscious rats. Am J Physiol 1994, 267:R536-R541.

25. Shkolnik A, Borut A: Temperature and water relations in two species of spiny mice (Acomys). J Mammal 1969, 50:245-255. 
26. Dickinson H, Moritz K, Wintour EM, Walker DW, Kett M: A comparative study of renal function in the desert-adapted spiny mouse and the laboratory adapted C57BL/6 mouse: response to dietary salt load. Am J Physiol 2007, 293(4):F1093-1098.

27. Cullen-McEwen LA, Kett MM, Dowling J, Anderson WP, Bertram JF: Nephron number, renal function, and arterial pressure in aged GDNF heterozygous mice. Hypertension 2003, 41:335-340.

28. Blantz RC, Peterson OW, Blantz ER, Wilson CB: Sexual differences in glomerular ultrafiltration: effect of androgen administration in ovariectomized rats. Endocrinology 1988, 122:767-773.

29. Munger K, Baylis C: Sex differences in renal hemodynamics in rats. Am J Physiol 1988, 254:F223-F231.

30. Remuzzi A, Puntorieri S, Mazzoleni A, Remuzzi G: Sex related differences in glomerular ultrafiltration and proteinuria in Munich-Wistar rats. Kidney Int 1988, 34:481-486.

31. Ota M, Crofton JT, Liu H, Festavan G, Share L: Increased plasma osmolality stimulates peripheral and central vasopressin release in male and female rats. Am J Physiol 1994, 267:R923-R928.

32. Stachenfeld NS, Splenser AE, Calzone WL, Taylor MP, Keefe DL: Sex differences in osmotic regulation of AVP and renal sodium handling. J Appl Physiol 2001, 91:1893-1901.

33. Wang YX, Edwards RM, Nambi P, Stack EJ, Pullen M, Share L, Crofton JT, Brooks DP: Sex difference in the antidiuretic activity of vasopressin in the rat. Am J Physiol 1993, 265:R1284-R1290.

34. Longhurst PA, Kauer J, Leggett RE, Levin RM: The influence of ovariectomy and estradiol replacement on urinary bladder function in rats. $J$ Urol 1992, 148:915-919

35. Nielsen S, Frokiaer J, Marples D, Kwon TH, Agre P, Knepper MA: Aquaporins in the kidney: from molecules to medicine. Physiol Rev 2002, 82:205-244.

36. Ecelbarger CA, Terris J, Frindt G, Echevarria M, Marples D, Nielsen S, Knepper MA: Aquaporin-3 water channel localization and regulation in rat kidney. Am J Physiol 1995, 269:F663-F672.

37. Burnier M, Monod ML, Chiolero A, Maillard M, Nussberger J, Brunner HR: Renal sodium handling in acute and chronic salt loading/depletion protocols: the confounding influence of acute water loading. J Hypertens 2000, 18:1657-1664.

38. Pechere-Bertschi A, Maillard M, Stalder H, Brunner HR, Burnier M: Blood pressure and renal haemodynamic response to salt during the normal menstrual cycle. Clin Sci (Lond) 2000, 98:697-702.

39. Pechere-Bertschi A, Burnier M: Gonadal steroids, salt-sensitivity and renal function. Curr Opin Nephrol Hypertens 2007, 16:16-21.

40. Kittikulsuth W, Looney SW, Pollock DM: Endothelin ETB receptors contribute to sex differences in blood pressure elevation in angiotensin II hypertensive rats on a high-salt diet. Clin Exp Pharmacol Physiol 2013, 40:362-370

41. Neugarten J: Gender and the progression of renal disease. J Am SoC Nephrol 2002, 13:2807-2809.

doi:10.1186/2042-6410-4-21

Cite this article as: Dickinson et al:: A comparative study of renal

function in male and female spiny mice - sex specific responses to a high salt challenge. Biology of Sex Differences 2013 4:21.

\section{Submit your next manuscript to BioMed Central and take full advantage of:}

- Convenient online submission

- Thorough peer review

- No space constraints or color figure charges

- Immediate publication on acceptance

- Inclusion in PubMed, CAS, Scopus and Google Scholar

- Research which is freely available for redistribution 